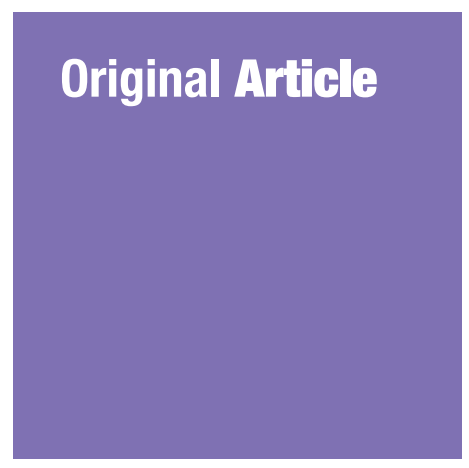

Submitted: 29 Aug 2020 Accepted: 6 Oct 2020 Online: 24 Feb 2021

\section{Short-Term Versus Long-Term Systemic Corticosteroid Use in the Acute Exacerbation of Chronic Obstructive Pulmonary Disease Patients}

\author{
Samah AlsheHri ${ }^{1}$, Mai Alalawi ${ }^{1}$, Abdulrahman MAKeEN ${ }^{2}$, \\ Ammar $\mathrm{JAD}^{2}$, Ahmed Alhuwaysi ${ }^{2}$, Mohammed Alageeli ${ }^{3}$, \\ Mohannad ALSHIBANI ${ }^{1}$
}

\author{
1 Department of Pharmacy Practice, Faculty of Pharmacy, King Abdulaziz \\ University, Jeddah, Saudi Arabia \\ 2 Faculty of Medicine, King Abdulaziz University, Jeddah, Saudi Arabia \\ 3 Faculty of Medicine, Ibn Sina National College for Medical Studies, Jeddah, \\ Saudi Arabia
}

To cite this article: Alshehri S, Alalawi M, Makeen A, Jad A, Alhuwaysi A, Alageeli M, Alshibani M. Short-term versus long-term systemic corticosteroid use in the acute exacerbation of chronic obstructive pulmonary disease patients. Malays J Med Sci. 2021;28(1):59-65. https://doi.org/10.21315/mjms2021.28.1.8

To link to this article: https://doi.org/10.21315/mjms2021.28.1.8

\begin{abstract}
Background: The administration of systemic corticosteroids in chronic obstructive pulmonary disease (COPD) exacerbation is the first line of management. The duration of this administration, however, is not well established in clinical practice. The objective of this study is to compare the clinical outcomes between short-term and long-term corticosteroid use in the acute exacerbation of COPD patients.

Methods: A single-centre, retrospective cohort study was conducted. From 2014 to 2018 , all patients over 40 years old with COPD who were admitted to the hospital with a case of COPD exacerbation and received systemic corticosteroids at presentation were included. The subjects were divided into two groups according to the duration of systemic corticosteroid therapy. The primary outcome was hospital re-admission within 180 days. The secondary outcomes were 30 days mortality and length of hospitalisation. The two groups were compared using an independent sample $t$-test, a Chi-square test, and a Mann-Whitney $U$ test, according to the data type.

Results: Eighty patients met the inclusion criteria. A total of $52(65 \%)$ patients completed long-term therapy, while 28 (35\%) patients were on short-term treatment. A total of 15 (28.8\%) patients reached the primary endpoint in the long-term treatment group versus $19(67.9 \%)$ in the short-term treatment group $(P=0.001)$. The 30-day mortality was $4(7.7 \%)$ and 0 (o\%), respectively, and the median length of hospitalisation was 6.5 and 7.5 days in the long-term group and short-term group, respectively $(P=0.32, P=0.88)$.

Conclusion: Long-term corticosteroid use in the management of acute COPD exacerbation was significantly associated with fewer 180 days re-admission. The duration of corticosteroid use remains controversial, and further studies are recommended to assess the relationship between patient profile and adherence to therapy post-discharge with re-exacerbation.
\end{abstract}

Keywords: COPD exacerbation, corticosteroids, re-admission, 30-day mortality, length of hospitalisation 


\section{Introduction}

Chronic obstructive pulmonary disease (COPD) is considered to be a complex, progressive life-threatening lung disease (1). It is characterised by chronic airflow obstruction that interferes with normal lung function, and it is not completely reversible (1). Acute COPD exacerbation happens when there is a deterioration of respiratory symptoms that necessitate additional therapy (1). COPD is associated with a high mortality rate; it is considered to be the fourth leading cause of death worldwide (2). By 2020, COPD is estimated to be the third leading cause of death worldwide (2). The administration of systemic corticosteroids, along with shortacting beta-2 agonists, is considered the first line of management in COPD exacerbation (3). Their rules have been established to reduce the frequency of exacerbations, minimise the urge of intubation, and lower the overall mortality rate $(3,4)$.

Previous studies have confirmed that corticosteroids are a cornerstone in the management of COPD exacerbation (3). Systemic corticosteroids have positive impacts on clinical outcomes, such as reducing re-admission rates within 180 days and accelerating the recovery of forced expiratory volume in the first second (FEV1) $(1,5)$. The duration of corticosteroid use in COPD exacerbation was studied in a randomised control trial (reduction in the use of corticosteroids in exacerbated COPD [REDUCE] trial), which was designed to compare the 5-day use (short-term) versus the 14-day use (longterm or conventional) (6). The study reported the non-inferiority of the short duration in terms of re-exacerbation within 6 months. On the contrary, short-term treatment significantly limited exposure to glucocorticoids and their adverse effects (6). The duration of systemic corticosteroid use is still not well established in clinical practice, and differences regarding administration were observed $(7,8)$.

The aim of this study is to investigate whether or not there are any differences in clinical outcomes between short-term versus long-term corticosteroid administration defined as re-admission within 180 days. The study also aims to compare the length of hospitalisation and mortality rate between the long-term group and the short-term group in treating acute exacerbated COPD.

\section{Methods}

A retrospective cohort study was conducted at a tertiary academic medical centre in Jeddah, Saudi Arabia. Approval was obtained from the Institutional Review Board (IRB). The screened data were from 2014 to 2018. The criteria for eligibility were all patients over 40 years old with a primary diagnosis of acute COPD exacerbation based on the Global Initiative for Chronic Obstructive Lung Disease (GOLD) diagnostic criteria who were admitted to hospital as a case of COPD exacerbation. In addition, the patients also had to be administered systemic corticosteroids at presentation. The exclusion criteria were patients with a history of asthma, pneumonia, home use of systemic corticosteroids prior to admission and unavailability of a treatment plan.

Data was extracted from electronic medical records using a standardised collection sheet that included demographics, comorbidities such as hypertension, diabetes, cardiovascular disease, endocrine disease, kidney disease, hepatic disease, smoking history and all data related to corticosteroid therapy (name, route, dose and duration). Patient characteristics during hospitalisation were also identified, including ICU admission, the requirement of mechanical ventilation and the length of hospitalisation. The primary outcome was the next exacerbation within 180 days. The secondary outcomes were mortality within 30 days and length of current hospitalisation. Baseline characteristics were described using measures of central tendency. The frequencies were presented as numbers (percentages). The two groups (short duration and long duration) were compared using an independent sample $t$-test, a Chi-square test, a Mann-Whitney U test and Fisher's exact test, according to the data type. A two-sided alpha level of less than 0.05 was considered to be statistically significant. SPSS software, version 21 (IBM, Chicago, IL, USA), was used for data analysis.

\section{Results}

\section{Study Population}

A total of 223 patients were evaluated for eligibility, of whom 80 patients met the inclusion criteria. The remaining 143 patients were excluded for various reasons. The majority 
of exclusions were patients who were diagnosed with community-acquired pneumonia and patients whose treatment plan was unavailable. Patients were divided into two groups based on the duration of corticosteroid therapy: longterm (conventional) duration and short-term duration. Long-term use is defined as $>5$ days of systemic corticosteroids, while short-term use is defined as $<5$ days of systemic corticosteroids (Figure 1).

\section{Baseline Characteristics}

A total of 52 patients completed longterm ( $>5$ days) therapy (65\%), while 28 were on short-term treatment (35\%). The mean age was 66.2 and 68.3 in the long-term and shortterm groups, respectively $(P=0.32)$. Regarding the sex of patients, $29(55.8 \%)$ in the longterm group and $18(64.3 \%)$ in the short-term group were male $(P=0.46)$. Saudi nationality accounted for $23(44.2 \%)$ and 15 (53.6\%) in the long-term and short-term groups, respectively
$(P=0.43)$. The most common comorbidities in our population were hypertension 10 (19.2\%) versus 10 (35.7\%), and diabetes 11 (21.2\%) versus $4(14.3 \%)$ in the long-term and shortterm groups, respectively. Other comorbidities in the short-term group included one patient with coronary artery disease, one patient with hypothyroidism and one patient with hyperthyroidism. One patient had heart failure in the long-term group. Smoking status was divided into two categories: 'ever smoke,' which accounted for $38(73.0 \%)$ versus $22(78.6 \%)$ and 'never smoke,' which accounted for 6 (11.5\%) versus 2 (7.1\%) in the long-term group and shortterm group, respectively. Twelve patients (23.1\%) in the long-term group and 5 patients (17.9\%) in the short-term were admitted to the intensive care unit (ICU) $(P=0.59)$. In addition, 11 patients $(21.2 \%)$ were on mechanical ventilation in the long-term group versus 2 patients $(7.1 \%)$ in the short-term group $(P=0.11)$. The baseline characteristics are illustrated in Table 1.

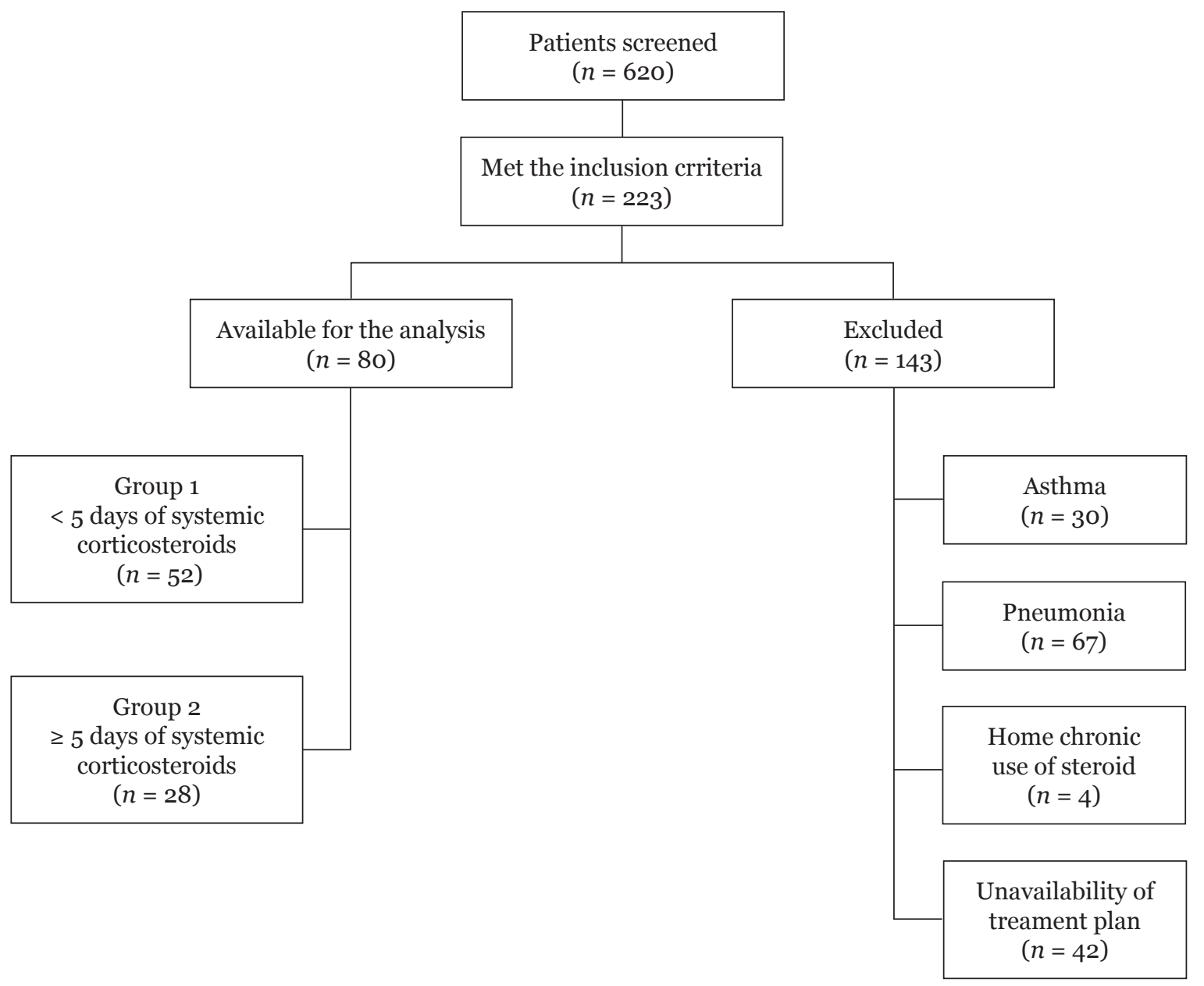

Figure 1. Flow of patients throughout the study 
Table 1. Baseline characteristics

\begin{tabular}{|c|c|c|c|c|}
\hline Characteristic & $\begin{array}{l}>5 \text { days } \\
(n=52)\end{array}$ & $\begin{array}{l}\leq 5 \text { days } \\
(n=28)\end{array}$ & $P$-value* & $\begin{array}{l}\text { All patients } \\
\quad(n=80)\end{array}$ \\
\hline Age, years $(\text { mean } \pm S D)^{*}$ & $66.2 \pm 1.6$ & $68.3 \pm 1.3$ & 0.32 & $67.0 \pm 10.3$ \\
\hline \multicolumn{5}{|l|}{ Sex, $n(\%)$} \\
\hline Male & $29(55.8)$ & $18(64.3)$ & 0.46 & $47(58.8)$ \\
\hline Female & $23(44.2)$ & $10(35 \cdot 7)$ & & $33(41.3)$ \\
\hline \multicolumn{5}{|l|}{ Nationality, $n$ (\%) } \\
\hline Saudi & $23(44.2)$ & $15(53.6)$ & 0.43 & $38(47.5)$ \\
\hline Non-Saudi & $29(55.8)$ & $13(46.4)$ & & $42(52.5)$ \\
\hline Comorbidity, $n$ (\%) & $22(42.3)$ & $15(53.6)$ & 0.34 & $37(46.3)$ \\
\hline $\mathrm{DM}, n(\%)$ & $11(21.2)$ & $4(14 \cdot 3)$ & 0.56 & $15(18.8)$ \\
\hline HTN, $n(\%)$ & $10(19.2)$ & $10(35 \cdot 7)$ & 0.10 & $20(25)$ \\
\hline Other, $n(\%)$ & $3(5.8)$ & $1(3.6)$ & 1.00 & $4(5)$ \\
\hline \multicolumn{5}{|l|}{ Smoking status, $n(\%)$} \\
\hline Ever smoke & $38(73.0)$ & $22(78.6)$ & 0.80 & $60(79.9)$ \\
\hline Never smoke & $6(11.5)$ & $2(7.1)$ & & $8(10)$ \\
\hline Not documented & $8(15.4)$ & $4(14 \cdot 3)$ & & $12(15)$ \\
\hline ICU admission, $n$ (\%) & $12(23.1)$ & $5(17 \cdot 9)$ & 0.59 & $17(21.3)$ \\
\hline Mechanical ventilation, $n$ (\%) & $11(21.2)$ & $2(7.1)$ & 0.13 & $13(16.3)$ \\
\hline
\end{tabular}

Notes: * $P$-values were calculated using Chi-square test for sex, nationality, comorbidities, smoking status, and ICU admission, independent sample $t$-test was used for age, Fisher's exact test was used for diabetes, other comorbidities, and mechanical ventilation; $\mathrm{SD}=$ standard deviation; $n=$ number; $\mathrm{DM}=$ diabetes mellitus; $\mathrm{HTN}$ = hypertension; ICU = intensive care unit

\section{Endpoints and Outcomes}

A total of 15 patients (28.8\%) were readmitted within 180 days in the long-term treatment group in comparison to 19 patients $(67.9 \%)$ in the short-term treatment group $(P=0.001)$ (Table 2$)$.

The 30-day mortality rates were $4(7.7 \%)$ and $\mathrm{o}(\mathrm{o} \%)$ in the long-term group and shortterm group, respectively $(P=0.13)$. The median length of hospitalisation was 6.5 and 7.5 days in the long-term group and short-term group, respectively $(P=0.88)$.

\section{Discussion}

We aimed to assess the use of corticosteroids in COPD exacerbation in a tertiary medical centre. Although GOLD guidelines state a clear recommendation of $5^{-7}$ days of treatment (1), the duration is still not well established in clinical practice, and differences regarding corticosteroid administration have been observed in previous studies $(7,8)$, as well as in our study.

Table 2. The outcomes of two groups of patients based on the duration of treatment

\begin{tabular}{|c|c|c|c|c|}
\hline Outcome & $\begin{array}{l}>5 \text { days } \\
(n=52)\end{array}$ & $\begin{array}{l}\leq 5 \text { days } \\
(n=28)\end{array}$ & $P$-value* & All patients \\
\hline Re-admission within 180 days, $n(\%)$ & $15(28.8)$ & $19(67.9)$ & 0.001 & $34(42.5)$ \\
\hline Mortality within 30 days, $n(\%)$ & $4(7.7)$ & $\mathrm{o}(\mathrm{o})$ & 0.29 & $4(5)$ \\
\hline Length of hospitalisation, days median [IQR] & $6.5[9]$ & $7.5[7]$ & 0.88 & $7[9]$ \\
\hline
\end{tabular}

Notes: * $P$-values were calculated using Chi-square for re-admission within 180 days; Mann-Whitney $\mathrm{U}$ test was used for length of hospitalisation; Fisher's exact test was used for mortality within 30 days; $n=$ number; IQR = interquartile range 
Our findings indicate a significant difference between the two treatment groups in terms of re-admission within 180 days, where more re-exacerbations occurred in the shortterm duration group $(P=0.001)$ compared to the long-term duration group. Our primary outcome was not consistent with the REDUCE randomised control trial that concluded the noninferiority (hazard ratio $=0.95 ; 90 \%$ CI: $0.70-$ 1.29) of short-term systemic corticosteroids as well as their advantage in decreasing the side effects related to corticosteroid exposure (6). Several explanations precipitate with the inconsistency of our primary outcome versus the REDUCE trial. The latter took place in Switzerland, as patients were screened for eligibility in five Swiss hospitals (6). The differing characteristics of our population, including adherence to medications and genetic factors, could be a reason why more re-exacerbations occurred in the short-term group. In addition, not all health care providers follow the updated guidelines for COPD management (9).

Our study population fell into the elderly category, where the mean age was $66.95 \pm 10.25$ years old. The elderly are well known for their poor adherence to and non-compliance with medications (10). Adherence to medications is a well-established factor that reduces the risk of recurrent exacerbation and improves the utilisation of different health care resources in COPD patients (11-13). However, especially in the Middle East, poor adherence to chronic medications has been documented for many diseases, including COPD (14). In addition, a cross-sectional study conducted in Saudi Arabia and Turkey that included 405 patients reported a high non-adherence percentage (49.2\%) in COPD patients. Approximately half of the patients had at least one episode of exacerbation (52.5\%) in the last year, with a higher ratio of exacerbations among Saudis (15). Besides considering the duration of corticosteroids received during hospitalisation, adherence can be an important factor affecting the number of readmissions that occurred in each group as well. Patient adherence was neither assessed in the REDUCE trial nor in our study. However, based on the literature, non-adherence has a direct impact on the increasing number of hospital admissions and mortality rates (16). A diversity of factors lay beyond poor adherence to therapy $(10,17)$ that are recommended to be assessed prospectively in further studies among COPD patients in Saudi Arabia.
Another outcome of our study was 30day mortality, which was insignificant between the two treatment groups $(P=0.132)$. Only four deaths occurred in the long-term group versus no deaths in the short-term group. Such findings were consistent with those reported in the REDUCE trial (hazard ratio = 0.93; 95\% CI: $0.40-2.20 ; P=0.87$ ) (6). Previous studies have revealed that a greater frequency of exacerbations is associated with an increased risk of death $(18,19)$. In addition, early re-admission after a recent discharge - particularly within 30 days - is positively associated with a higher risk of death (20). Two patients out of the four who died were re-admitted within 180 days as a case of re-exacerbation, which reflects the severity of the cases and the positive association of early re-admission and mortality.

We acknowledge some limitations in our study. The sample size was small, especially in the short-term group. Disease severity during hospitalisation was not measured, including FEV1 values, due to the lack of documentation. As this is the nature of a retrospective design, GOLD classification was not evaluated during admission. Nevertheless, previous studies have illustrated that FEV1 values between the two groups are similar $(6,21)$.

\section{Conclusion}

Long-term corticosteroid use in the management of acute COPD exacerbation was significantly associated with lower re-admission (180 days). The duration of corticosteroid use remains a controversy, and real clinical practice is different than the guideline recommendations. Further studies are recommended to assess patient profiles and adherence to therapy postdischarge and to establish whether these factors relate to re-admission despite corticosteroid duration.

\section{Acknowledgements}

None.

\section{Conflict of Interest}

None.

\section{Funds}

None. 


\section{Authors' Contributions}

Conception and design: SA, MA, MAS

Analysis and interpretation of the data: SA

Drafting of the article: SA, MAS

Critical revision of the article for important intellectual content: SA, MA, AM, AJ, AA, MAA, MAS

Final approval of the article: SA, MA, AM, AJ, AA, MAA, MAS

Collection and assembly of data: AM, AJ, AA, MAA

\section{Correspondence}

Assistant Professor Dr Samah Alshehri

PharmD (King Abdulaziz University),

MS (University of Arizona), BCPS

Department of Pharmacy Practice

King Abdulaziz University, Faculty of Pharmacy

Jeddah, Saudi Arabia PO Box 22252.

Tel: +966126400000/21146

Fax: +966126951696

E-mail: salshehri1@kau.edu.sa

\section{References}

1. Singh D, Agusti A, Anzueto A, Barnes PJ, Bourbeau J, Celli BR, et al. Global strategy for the diagnosis, management, and prevention of chronic obstructive lung disease: the GOLD Science Committee Report 2019. Eur Respir J. 2019;53(5). https://doi.org/10.1183/13993003 $.00164-2019$

2. Lozano R, Naghavi M, Foreman K, Lim S, Shibuya K, Aboyans V, et al. Global and regional mortality from 235 causes of death for 20 age groups in 1990 and 2010: a systematic analysis for the Global Burden of Disease Study 2010. Lancet. 2012;380(9859):2095-2128 https://doi.org/10.1016/So140-6736(12)61728-o

3. Woods JA, Wheeler JS, Finch CK, Pinner NA. Corticosteroids in the treatment of acute exacerbations of chronic obstructive pulmonary disease. Int $J$ Chron Obstruct Pulmon Dis. 2014;9:421-430. https://doi.org/10.2147/COPD . $\mathrm{S} 51012$
4. Niewoehner DE, Erbland ML, Deupree RH, Collins D, Gross NJ, Light RW, et al. Effect of systemic glucocorticoids on exacerbations of chronic obstructive pulmonary disease. Department of Veterans Affairs Cooperative Study Group. N Engl J Med. 1999;340(25):1941-1947. https://doi.org/10.1056/NEJM199906243402502

5. Cheng T, Gong Y, Guo Y, Cheng Q, Zhou M, Shi G, et al. Systemic corticosteroid for COPD exacerbations, whether the higher dose is better? a meta-analysis of randomized controlled trials. Clin Respir J. 2013;7(4):305-318. https://doi .org/10.1111/crj.12008

6. Leuppi JD, Schuetz P, Bingisser R, Bodmer M, Briel M, Drescher T, et al. Short-term vs conventional glucocorticoid therapy in acute exacerbations of chronic obstructive pulmonary disease: the REDUCE randomized clinical trial. JAMA. 2013;309(21):2223-231. https://doi.org/ 10.1001/jama.2013.5023

7. Zhang J, Zheng J, Huang K, Chen Y, Yang J, Yao W. Use of glucocorticoids in patients with COPD exacerbations in China: a retrospective observational study. Ther Adv Respir Dis. 2018;12:1753466618769514. https://doi.org/10 $.1177 / 1753466618769514$

8. Marcos PJ, Nieto-Codesido I, de Jorge Dominguez-Pazos S, Huerta A, Márquez E, Maiso A, et al. Treatment with systemic steroids in severe chronic obstructive pulmonary disease exacerbations: use of short regimens in routine clinical practice and their impact on hospital stay. Arch Bronconeumol. 2017;53(11):611-615. https://doi.org/10.1016/j.arbres.2017.03.012

9. Alsubaiei ME, Cafarella PA, Frith PA, McEvoy RD, Effing TW. Factors influencing management of chronic respiratory diseases in general and chronic obstructive pulmonary disease in particular in Saudi Arabia: an overview. Ann Thorac Med. 2018;13(3):144-149. https://doi .org/10.4103/atm.ATM_293_17.

10. Sanduzzi A, Balbo P, Candoli P, Catapano GA, Contini P, Mattei A, et al. COPD: adherence to therapy. Multidiscip Respir Med. 2014;9(1):60. https://doi.org/10.1186/2049-6958-9-6o 
11. Toy EL, Beaulieu NU, McHale JM, Welland TR, Plauschinat CA, Swensen A, et al. Treatment of COPD: relationships between daily dosing frequency, adherence, resource use, and costs. Respir Med. 2011;105(3):435-441. https://doi .org/10.1016/j.rmed.2010.09.006

12. Mäkelä MJ, Backer V, Hedegaard M, Larsson K. Adherence to inhaled therapies, health outcomes and costs in patients with asthma and COPD. Respir Med. 2013;107(10):1481-1490. https://doi.org/10.1016/j.rmed.2013.04.005

13. Jardim JR, Nascimento OA. The importance of inhaler adherence to prevent COPD exacerbations. Med Sci (Basel). 2019;7(4). https://doi.org/10.3390/medsci7040054

14. Al-Qasem A, Smith F, Clifford S. Adherence to medication among chronic patients in Middle Eastern countries: review of studies. East Mediterr Health J. 2011;17(4):356-363.

15. Kokturk N, Polatli M, Oguzulgen IK, Saleemi S, Al Ghobain M, Khan J, et al. Adherence to COPD treatment in Turkey and Saudi Arabia: results of the ADCARE study. Int J Chron Obstruct Pulmon Dis. 2018;13:1377-1388. https://doi.org/10.2147/ COPD.S150411

16. van Boven JF, Chavannes NH, van der Molen T, Rutten-van Mölken MP, Postma MJ, Vegter S. Clinical and economic impact of non-adherence in COPD: a systematic review. Respir Med. 2014;108(1):103-113. https://doi.org/10.1016/ j.rmed.2013.08.044
17. Humenberger M, Horner A, Labek A, Kaiser B, Frechinger R, Brock C, et al. Adherence to inhaled therapy and its impact on chronic obstructive pulmonary disease (COPD). BMC Pulm Med. 2018;18(1):163. https://doi.org/10.1186/s12890 $-018-0724-3$

18. Prudente R, Franco EAT, Mesquita CB, Ferrari R, de Godoy I, Tanni SE. Predictors of mortality in patients with COPD after 9 years. Int $J$ Chron Obstruct Pulmon Dis. 2018;13:3389-3398. https://doi.org/10.2147/COPD.S174665

19. Esteban C, Castro-Acosta A, Alvarez-Martínez CJ, Capelastegui A, López-Campos JL, PozoRodriguez F. Predictors of one-year mortality after hospitalization for an exacerbation of COPD. BMC Pulm Med. 2018;18(1):18. https://doi .org/10.1186/s12890-018-0574-Z

20. Shin B, Kim SH, Yong SJ, Lee WY, Park S, Lee SJ, et al. Early readmission and mortality in acute exacerbation of chronic obstructive pulmonary disease with community-acquired pneumonia. Chron Respir Dis. 2019;16:1479972318809480. https://doi.org/10.1177/1479972318809480

21. Vondracek SF, Hemstreet BA. Retrospective evaluation of systemic corticosteroids for the management of acute exacerbations of chronic obstructive pulmonary disease. Am $J$ Health Syst Pharm. 2006;63(7):645-652. https://doi.org/10.2146/ajhpo50316 